Marquette University

e-Publications@Marquette

Biomedical Engineering Faculty Research and

Publications

Biomedical Engineering, Department of

2012

\title{
Including Aortic Valve Morphology in Computational Fluid \\ Dynamics Simulations: Initial Findings and Application to Aortic Coarctation
}

\author{
David C. Wendell \\ Marquette University \\ Margaret M. Samyn \\ Marquette University \\ Joseph Richard Cava \\ Marquette University \\ Laura M. Ellwein \\ Marquette University, laura.ellwein@marquette.edu \\ Mary M. Krolikowski \\ Herma Heart Center Children's Hospital of Wisconsin
}

See next page for additional authors

Follow this and additional works at: https://epublications.marquette.edu/bioengin_fac

Part of the Biomedical Engineering and Bioengineering Commons

\section{Recommended Citation}

Wendell, David C.; Samyn, Margaret M.; Cava, Joseph Richard; Ellwein, Laura M.; Krolikowski, Mary M.; Gandy, Kimberly L.; Pelech, Andrew N.; Shadden, Shawn C.; and LaDisa, John F., "Including Aortic Valve Morphology in Computational Fluid Dynamics Simulations: Initial Findings and Application to Aortic Coarctation" (2012). Biomedical Engineering Faculty Research and Publications. 40.

https://epublications.marquette.edu/bioengin_fac/40 


\section{Authors}

David C. Wendell, Margaret M. Samyn, Joseph Richard Cava, Laura M. Ellwein, Mary M. Krolikowski, Kimberly L. Gandy, Andrew N. Pelech, Shawn C. Shadden, and John F. LaDisa 


\title{
Including Aortic Valve Morphology in Computational Fluid Dynamics Simulations: Initial Findings and Application to Aortic Coarctation
}

\author{
David C. Wendell \\ Department of Biomedical Engineering, Marquette University \\ Milwaukee, WI \\ Margaret M. Samyn \\ Department of Biomedical Engineering, Marquette University \\ Department of Pediatrics, Herma Heart Center Children's \\ Hospital of Wisconsin \\ Milwaukee, WI \\ Joseph R. Cava \\ Department of Biomedical Engineering, Marquette University \\ Department of Pediatrics, Herma Heart Center Children's \\ Hospital of Wisconsin \\ Milwaukee, WI \\ Laura M. Ellwein \\ Department of Biomedical Engineering, Marquette University \\ Milwaukee, WI \\ Mary M. Krolikowski \\ Department of Pediatrics, Herma Heart Center Children's \\ Hospital of Wisconsin \\ Milwaukee, WI
}

Medical Engineering and Physics, Vol. 35, No. 6 (June 2013): pg. 723-735. DOI. This article is @ Elsevier and permission has been granted for this version to appear in e-Publications@Marquette. Elsevier does not grant permission for this article to be further copied/distributed or hosted elsewhere without the express permission from Elsevier. 
NOT THE PUBLISHED VERSION; this is the author's final, peer-reviewed manuscript. The published version may be accessed by following the link in the citation at the bottom of the page.

\author{
Kimberly L. Gandy \\ Department of Pediatrics, Children's Mercy Hospitals \& Clinics \\ Kansas City, MO \\ Andrew N. Pelech \\ Department of Pediatrics, Herma Heart Center Children's \\ Hospital of Wisconsin \\ Milwaukee, WI \\ Shawn C. Shadden \\ Department of Mechanical, Materials, and Aerospace \\ Engineering, Illinois Institute of Technology \\ Chicago, IL \\ John F. LaDisa, Jr. \\ Department of Biomedical Engineering, Marquette University \\ Department of Pediatrics, Herma Heart Center Children's \\ Hospital of Wisconsin \\ Department of Medicine, Division of Cardiovascular Medicine, \\ Medical College of Wisconsin \\ Milwaukee, WI
}

\title{
Abstract
}

Computational fluid dynamics (CFD) simulations quantifying thoracic aortic flow patterns have not included disturbances from the aortic valve (AoV). $80 \%$ of patients with aortic coarctation (CoA) have a bicuspid aortic valve (BAV) which may cause adverse flow patterns contributing to morbidity. Our objectives were to develop a method to account for the AoV in CFD simulations, and quantify its impact on local hemodynamics. The method developed facilitates segmentation of the AoV, spatiotemporal interpolation of segments, and anatomic positioning of segments at the CFD model inlet. The AoV was included in CFD model examples of a normal (tricuspid AoV) and a post-surgical CoA patient (BAV). Velocity, turbulent kinetic energy (TKE), time-averaged wall shear stress (TAWSS), and oscillatory shear index (OSI) results were compared to equivalent simulations using a plug inlet profile. The plug inlet greatly underestimated TKE for both examples. TAWSS differences extended throughout the thoracic aorta for the CoA BAV, but were limited to the arch for the normal example. OSI differences existed mainly in the ascending aorta for both cases. The impact of AoV can now be included with

Medical Engineering and Physics, Vol. 35, No. 6 (June 2013): pg. 723-735. DOI. This article is ( Elsevier and permission has been granted for this version to appear in e-Publications@Marquette. Elsevier does not grant permission for this article to be further copied/distributed or hosted elsewhere without the express permission from Elsevier. 
NOT THE PUBLISHED VERSION; this is the author's final, peer-reviewed manuscript. The published version may be accessed by following the link in the citation at the bottom of the page.

CFD simulations to identify regions of deleterious hemodynamics thereby advancing simulations of the thoracic aorta one step closer to reality.

Keywords: magnetic resonance imaging (MRI), congenital heart disease, phase-contrast MRI, bicuspid aortic valve, kinetic energy, shear stress, hemodynamics, turbulence

\section{Introduction}

The aortic valve (AoV) is normally a tricuspid structure. The prevalence of a bicuspid aortic valve (BAV) is 2\% in the general population [1], but $50-80 \%$ in patients with coarctation of the aorta $(\mathrm{CoA})[1,2]$. CoA is one of the most common congenital cardiovascular defects affecting 3,000 to 4,000 births annually in the U.S. $[3,4]$, and is defined by a narrowing of the proximal descending thoracic aorta ( $d A o$ ) in the region of the ductus arteriosus. The prevalence of BAV in CoA is particularly concerning as reports have documented a nine-fold increased risk of dissection in the ascending aorta (AscAo), often occurring at younger ages in patients with BAV [1]. Studies using Doppler ultrasound [5] and 4D magnetic resonance imaging (MRI) flow measurements [6] have also indicated a BAV causes flow disturbances in the AscAo associated with progressive dilatation beyond that associated with a tricuspid valve. While some turbulence normally exists in the aortic arch $[7,8]$, diseases of the AoV frequently show pronounced turbulence in this region [9]. These findings suggest CoA patients with a BAV may experience altered hemodynamics in the AscAo that could lead to local pathology.

Many CoA patients suffer reduced life expectancy despite surgical or catheter-based treatment [10]. Nearly all long-term problems after treatment for CoA can be explained on the basis of abnormal hemodynamics and vascular biomechanics [11]. Understanding the hemodynamic basis of morbidity and treatment outcomes for these patients, as well as their association with AoV morphology, can be aided by recent advancements in computational modeling tools that use data obtained by a routine clinical MRI [12, 13]. Anatomic data, in concert with physiological data such as flow assessment by phase-contrast MRI (PC-MRI) and bilateral upper and lower blood pressure (BP) measurements, can be used to create 3D patient-specific representations of vascular hemodynamics throughout

Medical Engineering and Physics, Vol. 35, No. 6 (June 2013): pg. 723-735. DOI. This article is (C) Elsevier and permission has been granted for this version to appear in e-Publications@Marquette. Elsevier does not grant permission for this article to be further copied/distributed or hosted elsewhere without the express permission from Elsevier. 
the cardiac cycle $[14,15]$ using computational fluid dynamics (CFD) simulations. These simulations provide local wall shear stress (WSS) indices shown to correlate with disease $[16,17]$ in a manner not possible with other imaging modalities.

CFD simulations offer great promise for the field of congenital cardiac surgery and catheter intervention. If specific physiological and structural outcomes are related to adverse hemodynamics, investigation of modifications that restore more favorable flow patterns could be used to design optimal treatments. This approach has been successfully applied to congenital heart defects resulting in a single ventricle physiology where CFD simulations of the Fontan procedure have led to several technical modifications demonstrated to be hemodynamically superior to previous surgical techniques [18].

The objectives of the current investigation were to develop a procedure to incorporate the local flow alterations introduced by the AoV into subject-specific CFD simulations, and to quantify the impact of valve morphology on thoracic aortic hemodynamics. The organization begins with a description of the methods developed for this purpose, which were then applied in two examples. CFD models were generated for a patient with a tricuspid AoV (TRI) and a normal aortic arch, as well as for the surgically corrected CoA arch of a patient with a BAV. For each example, alterations in hemodynamics induced by the valve are determined by comparing results including the AoV with those obtained from a more common approach using an assumed plug inlet velocity profile.

\section{Materials and Methods}

\section{Magnetic Resonance Imaging}

Patients with prior diagnosis of congenital cardiovascular disease underwent clinically indicated cardiac MRI studies. IRB approval allowed use of anonymized patient data for this research after each patient/guardian signed assent/consent. Two subjects exhibiting Roman arches (normal/TRI: 13 y/o female, CoA/BAV: 34 y/o male) were selected to test applicability of the methods presented below with

Medical Engineering and Physics, Vol. 35, No. 6 (June 2013): pg. 723-735. DOI. This article is (C) Elsevier and permission has been granted for this version to appear in e-Publications@Marquette. Elsevier does not grant permission for this article to be further copied/distributed or hosted elsewhere without the express permission from Elsevier. 
patient populations commonly exhibiting different valve morphologies (Figure 1a1, 1a3 [19]).
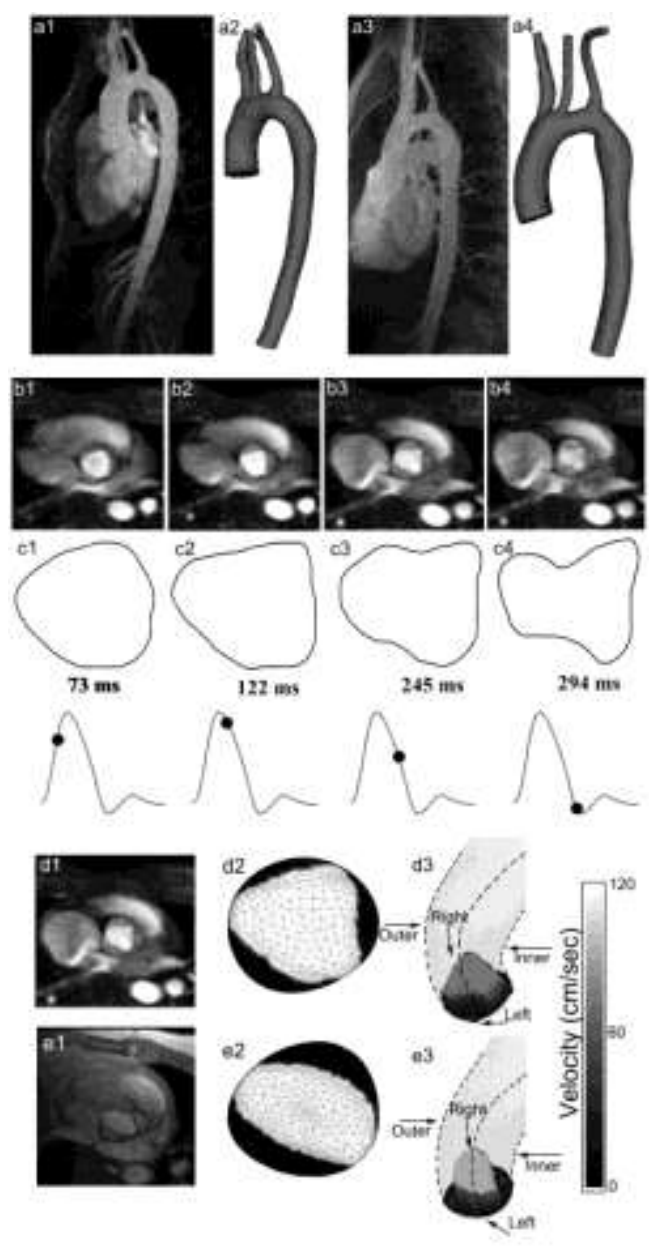

\section{Figure 1}

Method of patient-specific model construction and valve inclusion. Imaging data, displayed as maximum intensity projections (a1, a3), were used to create 3D CFD models (a2, a4). Temporal PC-MRI magnitude images showing valve leaflets at specific times during systole (b1-b4) were segmented and smoothed with a custom-designed MATLAB program ( $\mathrm{c} 1-\mathrm{c} 4)$ for example patients having tricuspid (d1) and bicuspid aortic valves (e1). These segmentations were applied to the CFD model inflow to create a time-varying mask of the inflow face for the tricuspid (d2) and bicuspid (e2) valves. Resulting velocity profile assigned to the inflow face using the mask (d3, e3).

Gadolinium-enhanced ( $0.4 \mathrm{ml} / \mathrm{kg}$; gadodiamide, Omniscan $\AA$, GE Healthcare, Waukesha, WI) MR angiography (MRA) was performed with a breath-held 3D fast gradient echo sequence using a $1.5 T$ Symphony ${ }^{\circledR}$ scanner (Siemens Healthcare, Erlangen, Germany). Slice thickness was $2.0 \mathrm{~mm}$, with 56-60 sagittal slices per volume. A 
$384 \times 192$ acquisition matrix (reconstructed to $384 \times 256$ ) was used with a field of view (FoV) of $25 \times 42 \mathrm{~cm}^{2}$ (spatial resolution of $0.65 \times 1.64$ $\mathrm{mm}$ ). Other parameters included a repetition time (TR) of $4.3 \mathrm{~ms}$, echo time (TE) of $1.4 \mathrm{~ms}$, and a flip angle of $25^{\circ}$.

Time-resolved, velocity encoded 2D anatomic and through-plane PC-MRI was performed orthogonally in the AscAo, near the main pulmonary artery, in the descending thoracic aorta at the level of the diaphragm, and orthogonal to the arch origins of the head and neck vessels. Heart rates ranged from 82-92 bpm during which twenty-five images were reconstructed. Imaging parameters included $T R, T E$, and flip angle of $46 \mathrm{~ms}, 3.8 \mathrm{~ms}$, and $30^{\circ}$, respectively. The FoV was $30 \times 22.5 \mathrm{~cm}^{2}$ with an acquisition matrix of $256 \times 192$, and a slice thickness of $7 \mathrm{~mm}$, resulting in a voxel size of $1.17 \mathrm{~mm} \times 1.17 \mathrm{~mm} \times$ $7 \mathrm{~mm}$. Subjects breathed freely and data was retrospectively gated to the cardiac cycle. Average and peak AscAo flow rates and Reynolds are provided in Table 1. After scanning, supine, bilateral upper and lower extremity BP assessment was performed using a Dinamap BP system (GE Healthcare, Waukesha, WI).

\begin{tabular}{|l|c||c||c|c||}
\hline & Qmean $_{\text {(mL/sec })}$ & Qpeak $_{\text {(mL/sec }}$ & $\boldsymbol{R e}_{\text {mean }}$ & $\boldsymbol{R e}_{\text {peak }}$ \\
\hline Normal & 113.6 & 380.6 & 1405 & 4704 \\
\hline CoA & 131.6 & 471.5 & 1485 & 5317 \\
\hline
\end{tabular}

Table 1 Mean and peak blood flow characteristics in the ascending aorta of patients

\section{Computational model construction}

CFD models were created using SimVascular (https://simtk.org) [20] as discussed elsewhere [21]. Models originated at the sinotubular junction and extended to the diaphragm, including the innominate (IA), right (RCCA) and left (LCCA) common carotid, and right (RSCA) and left (LSCA) subclavian arteries (Fgure 1a2, 1a4). Models were discretized into a finite element mesh using a commercially available, automatic, adaptive mesh generation program (MeshSim, Simmetrix, Clifton Park, NY). 


\section{Specification of inflow boundary conditions}

The general approach applied to include the influence of an aortic valve into CFD simulations for the current investigation is introduced here, and followed by specific details in the subsequent paragraphs. A time varying blood flow waveform was obtained in the AscAo downstream of the valve for each patient by integrating velocity values within the defined lumen cross section. For valve cases, a timevarying plug flow inlet based on the measured AscAo flow was created, but with a restricted cross-section determined from time-varying PCMRI magnitude data at the level of the valve. CFD results from this approach of using a masked time-varying inlet plug velocity were then compared to those from the more common approach of using an unmasked time-varying plug blood flow velocity profile.

PC-MRI data was used to calculate time-resolved volumetric blood flow $[22,23]$ using specialized software (Segment; http://segment.heiberg.se). Eddy current compensation was performed [24] and instantaneous flow rates were computed by integrating velocities within defined lumen cross sections [25]. AscAo PC-MRI data were used to create inflow waveforms using a Fourier interpolation method where the number of simulation time steps was determined for a Courant-Friedrichs-Lewy (CFL) condition $<1$. Prior CFD models of the thoracic aorta used an assumed inflow profile [14, $26,27]$. Thus, simulations for each patient were initially run with a time-varying plug velocity profile across the entire inlet face and compared to simulations where the inflow profile was restricted by the time-varying area delineated by the patient-specific AoV as discussed below.

\section{Delineating aortic valve morphology}

Additional PC-MRI series through the AoV were used to create spatiotemporally varying CFD model inlets reflective of AoV position (Figure 1b1-1b4). The CoA patient featured here presented with the most common type of BAV (type I, right-left leaflet fusion: $75-80 \%$ ) [28].

Medical Engineering and Physics, Vol. 35, No. 6 (June 2013): pg. 723-735. DOI. This article is (C) Elsevier and permission has been granted for this version to appear in e-Publications@Marquette. Elsevier does not grant permission for this article to be further copied/distributed or hosted elsewhere without the express permission from Elsevier. 
NOT THE PUBLISHED VERSION; this is the author's final, peer-reviewed manuscript. The published version may be accessed by following the link in the citation at the bottom of the page.

The AoV was included using a custom-designed MATLAB $\mathbb{R}$ program (MathWorks, Natick, MA) that allows a user to segment the opening defined by valve leaflets (i.e. lumen) and surrounding sinuses for each image in the cardiac cycle (Figure 1c1-1c4). Segmentations were translated into polar coordinates relative to the center of the segmentation and interpolated to obtain values at $1^{\circ}$ increments. These values were translated back into Cartesian coordinates, no longer limited by the pixel resolution of the MRI images, and thereby more reflective of valve morphology. The valve lumen was scaled by its maximum radius to create a template applicable to any inlet face. This is particularly important as the inlet face of the model may not exactly correspond with the plane of the valve PC-MRI image. Segmentations of the aortic sinuses were not mapped to the inlet face, but rather used to calculate any deviation from the center of the vessel.

\section{Implementing AoV segmentations into CFD models}

Valve segments were loaded into MATLAB® with their corresponding temporally varying plug inflow velocity components (described above). Segments were linearly interpolated for each time point in the simulation ( CFL condition $<1$ ). These segments were mapped to the area of the inlet face after translating and rotating their position to place leaflets in their correct anatomic location. The distance from the center of the vessel to each node on the inlet mesh face was calculated and compared to each temporal segmentation. Regions of the inlet face were assigned a 1 or 0 depending on whether they were inside or outside the valve opening, creating a binary mask for each time point (Figure 1d2, 1e2). Velocities for nodes that lie on the interior of the valve opening were then scaled by the reduction in area caused by valve tissue encroaching on the flow domain (Figure $1 \mathrm{~d} 3,1 \mathrm{e} 3)$.

\section{Outflow boundary conditions and CFD simulations}

To replicate the physiologic effect of arterial networks distal to CFD model branches, three-element Windkessel model outlet boundary conditions were imposed from flow waveforms and measured BP data

Medical Engineering and Physics, Vol. 35, No. 6 (June 2013): pg. 723-735. DOI. This article is (C) Elsevier and permission has been granted for this version to appear in e-Publications@Marquette. Elsevier does not grant permission for this article to be further copied/distributed or hosted elsewhere without the express permission from Elsevier. 
using a coupled-multidomain method [29] as described in detail elsewhere [26].

Newtonian and incompressible fluid assumptions were employed (viscosity and density of $4 \mathrm{cP}$ and $1.06 \mathrm{~g} / \mathrm{cm}^{3}$, respectively) consistent with previous studies and upon consideration of shear rates in this portion of the vasculature [14]. Simulations were performed using a stabilized finite element solver with the LesLib commercial linear solver (Altair Engineering Inc., Troy, MI) to solve equations for conservation of mass (continuity) and balance of fluid momentum (Navier-Stokes). Meshes contained $>3$ million tetrahedral elements with localized refinement, using an adaptive technique $[30,31]$ to deposit more elements near the luminal surface, at the boundary of the valve leaflets, and in regions prone to flow disruption. Convergence criteria included residual errors $<10^{-3}$ and a minimum of six non-linear iterations per time step. Simulations were run until the flow rate and BP fields stabilized yielding periodic solutions for five consecutive cycles ( $<1 \%$ difference between BP and flow values in consecutive cycles).

\section{Quantification of hemodynamic indices}

Blood flow velocity and indices of WSS were visualized using ParaView (Kitware, Inc., Clifton Park, NY). The calculation of timeaveraged WSS (TAWSS) was employed based on established methods [32]. Low TAWSS is thought to promote atherogenesis, as is elevated oscillatory shear index (OSI), a dimensionless index of directional changes in WSS. Low OSI indicates WSS is unidirectional, while a value of 0.5 is indicative of bidirectional WSS with a time-average value of zero [33]. Previous imaging studies found local low TAWSS values that were statistically different from circumferential averages [16], which motivates the need to report detailed local WSS indices in CFD studies. Briefly, the surface of each vessel was unwrapped and mapped into a $\theta$, I rectangular domain, where $\theta$ and I are the circumferential and longitudinal coordinates of each point on the vessel wall. A 2D moving average filter was then applied, using 5 points circumferentially and 3 points longitudinally to generate local circumferential and longitudinal TAWSS and OSI results. Identical

Medical Engineering and Physics, Vol. 35, No. 6 (June 2013): pg. 723-735. DOI. This article is (C) Elsevier and permission has been granted for this version to appear in e-Publications@Marquette. Elsevier does not grant permission for this article to be further copied/distributed or hosted elsewhere without the express permission from Elsevier. 
locations were queried for each patient across inlet types, providing insight into how inlet conditions impact indices of WSS.

TAWSS results from simulations using plug velocity profiles ( $\tau_{\text {no- }}$ valve) were used as the baseline when comparing to those including the impact of the AoV ( $\left.\tau_{\text {valve }}\right)$. $\tau_{\text {valve }}$ results were mapped to the computational mesh used to obtain $\tau_{n o-v a l v e}$. The mapped results were then subtracted and normalized to $\tau_{n o-v a l v e}$ at each spatial location $\left(x_{j}\right)$ using:

$$
\varepsilon_{\text {inlet }}\left(x_{j}\right)=\frac{\tau_{\text {valve }}\left(x_{j}\right)-\tau_{\text {no-valve }}\left(x_{j}\right)}{\max \left[\tau_{\text {no-valve }}\left(x_{j}\right), \tau_{\text {mean-dAo }}\right]}
$$

Mean values in the dAo $\left(\tau_{\text {mean-DAo }}\right)$ were used for normalization in regions of low WSS in the plug simulation to prevent the overestimation of error at these points similar to previously published techniques [34]. Locations in each model where the influence of the inflow waveform was greater than established levels of inter-observer variability [35] were then identified.

\section{Turbulent Kinetic Energy}

To investigate turbulence resulting from arch geometry and inlet condition, cycle-to-cycle variation within the velocity field were determined by computing the turbulent kinetic energy (TKE) [21,36]. Briefly, four additional cardiac cycles were simulated once the simulations had converged to the criteria above, resulting in five wellconverged cycles. An ensemble average for each time point within the cardiac cycle was then computed over the last five cycles. Subtracting the ensemble averaged cycle from the original velocity field results in the fluctuating component of the velocity, $\overrightarrow{\tilde{u}}(\vec{x}, t)$ that can be used to compute the turbulent kinetic energy as

$$
\operatorname{TKE}(\vec{x}, s)=\frac{1}{2} \rho\left[\left\langle\tilde{u}_{1}^{2}\right\rangle(\vec{x}, s)+\left\langle\tilde{u}_{2}^{2}\right\rangle(\vec{x}, s)+\left\langle\tilde{u}_{3}^{2}\right\rangle(\vec{x}, s)\right], \quad \forall s \in[0, T)
$$


where $T$ is the period, $\rho$ is the density of blood, $\tilde{u}_{1}, \tilde{u}_{2}$, and $\tilde{u}_{3}$ represent the $x, y$, and $z$ components of the fluctuating velocity, and $\langle\vec{x}\rangle$ denotes the ensemble mean. The ensemble averaged kinetic energy (KE) was also computed as

$$
\mathrm{KE}(\vec{x}, s)=\frac{1}{2} \rho\left[\left\langle u_{1}^{2}\right\rangle(\vec{x}, s)+\left\langle u_{2}^{2}\right\rangle(\vec{x}, s)+\left\langle u_{3}^{2}\right\rangle(\vec{x}, s)\right], \quad \forall s \in[0, T)
$$

where $u_{1}, u_{2}$, and $u_{3}$ represents the $x, y$, and $z$ components of the ensemble averaged velocity. The ratio of TKE \KE was also computed.

To interpret TKE results, the aortic arch was isolated from the head and neck vessels and then examined in three sections: AscAo, transverse arch, and dAo. Mean TKE, KE, and TKE/KE at peak systole, mid-deceleration, and mid-diastole were quantified in each region to determine the impact of the inlet condition.

\section{Results}

\section{Example 1: Normal Aortic Arch and Tricuspid AoV}

\section{Blood Flow Velocity}

There was good agreement between blood flow waveforms acquired via PC-MRI compared to plug and TRI blood flow simulations (Figure 2). Early systolic peaks in simulation, as compared to in PCMRI, waveforms were noted at most measurement locations since simulations were run with rigid walls. Velocity profiles during systole were therefore elevated for TRI and plug simulations compared to PCMRI (acquired separately from AscAo PC-MRI) for a given time point (egs. dAo 102 and $153 \mathrm{~ms}$ ). In contrast, velocity profiles were similar in the AscAo and proximal dAo where simulation and measured waveforms were most alike. In these locations direct comparison of spatial values is appropriate, TRI simulations produced velocity profiles that were in greater agreement with PC-MRI than those from plug simulations (eg. AscAo $147 \mathrm{~ms}$ ). 


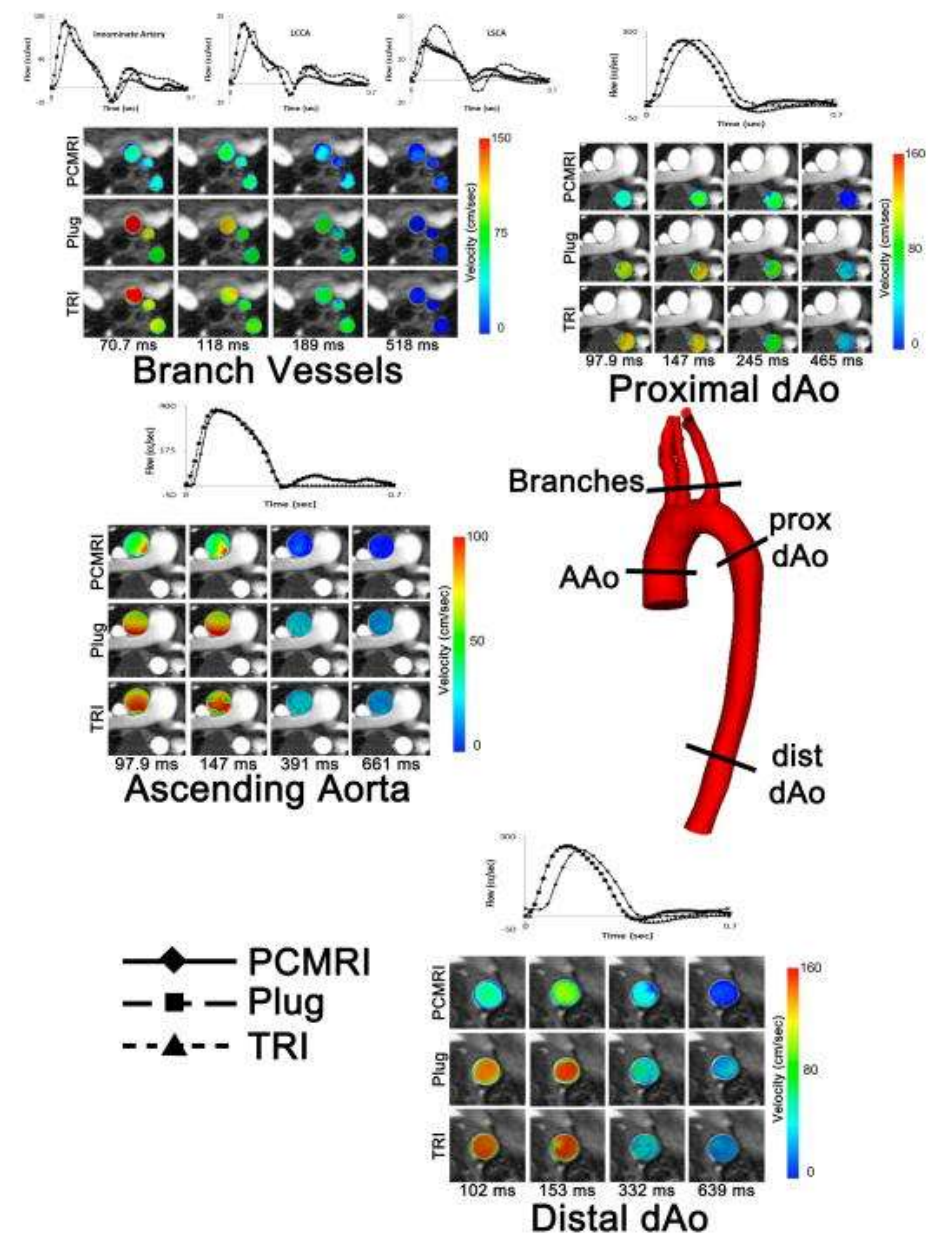

Figure 2

Comparison of blood flow velocity waveforms between PC-MRI (solid line), plug (dashed line), and TRI (dotted line) inlet conditions in the AscAo, proximal and distal dAo, IA, LCCA, and LSCA for the normal patient from example 1. Velocity profiles are also presented for 4 time points throughout the cardiac cycle (two during systole as well as in early and late diastole).

Analysis of temporal streamlines revealed AoV flow patterns are most remarkable at peak systole. During this time flow disturbances extended along the outer wall of the AscAo for the TRI simulation, but are almost non-existent for the plug inflow (Figure 3, top). The influence of the AoV on downstream velocity profiles exists within the AscAo (Figure 3; top velocity profile and vector inserts) and persists distally. The precise location beyond which the TRI AoV no longer impacts hemodynamics is discussed in the localized quantification section below. 


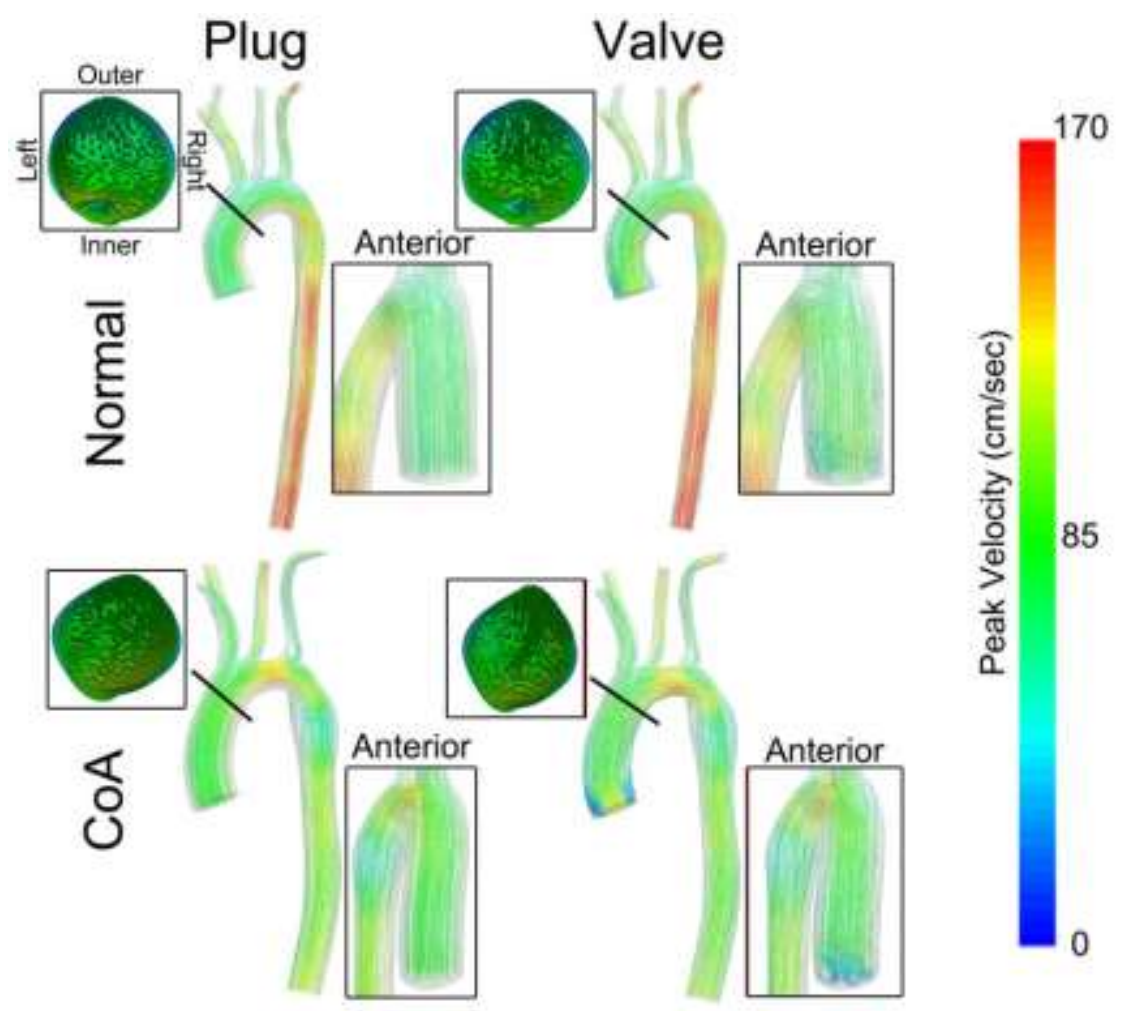

\section{Figure 3}

Blood flow velocity streamlines at peak systole for simulations run with plug (left column) or valve (right column) inlet conditions. Results from the normal patient in example 1 are shown along the top row while results from the CoA patient with a BAV from example 2 are shown along the bottom row. Inserts reveal velocity profiles and associated vectors in the ascending aorta downstream of the valve leaflets.

\section{Wall shear stress}

Local TAWSS along the longitudinal axis of the aorta is summarized for the inner and outer curvatures and anatomic left and right luminal surfaces in Figure 4. TAWSS disparity between inlet types was most pronounced within the AscAo along the inner right and outer left curvatures while differences at other locations were more modest. These differences extended to the mid-transverse arch, but dropped considerably distal of the LSCA. TAWSS quantified circumferentially in the AscAo, transverse arch, and dAo are also shown in Figure 4. The largest disparity in TAWSS occurred $\sim 1 \mathrm{dAo}$ diameter proximal to the IA along the inner right wall (Figure 4B, $19.8 \mathrm{dyn} / \mathrm{cm}^{2}$ ). Differences in TAWSS related to inclusion of the TRI AoV in CFD simulations were greater than those caused by inter-observer variability for $72 \%$ of the 
luminal surface in the AscAo, as compared to only $32 \%$ of the dAo (Figure 5, left).

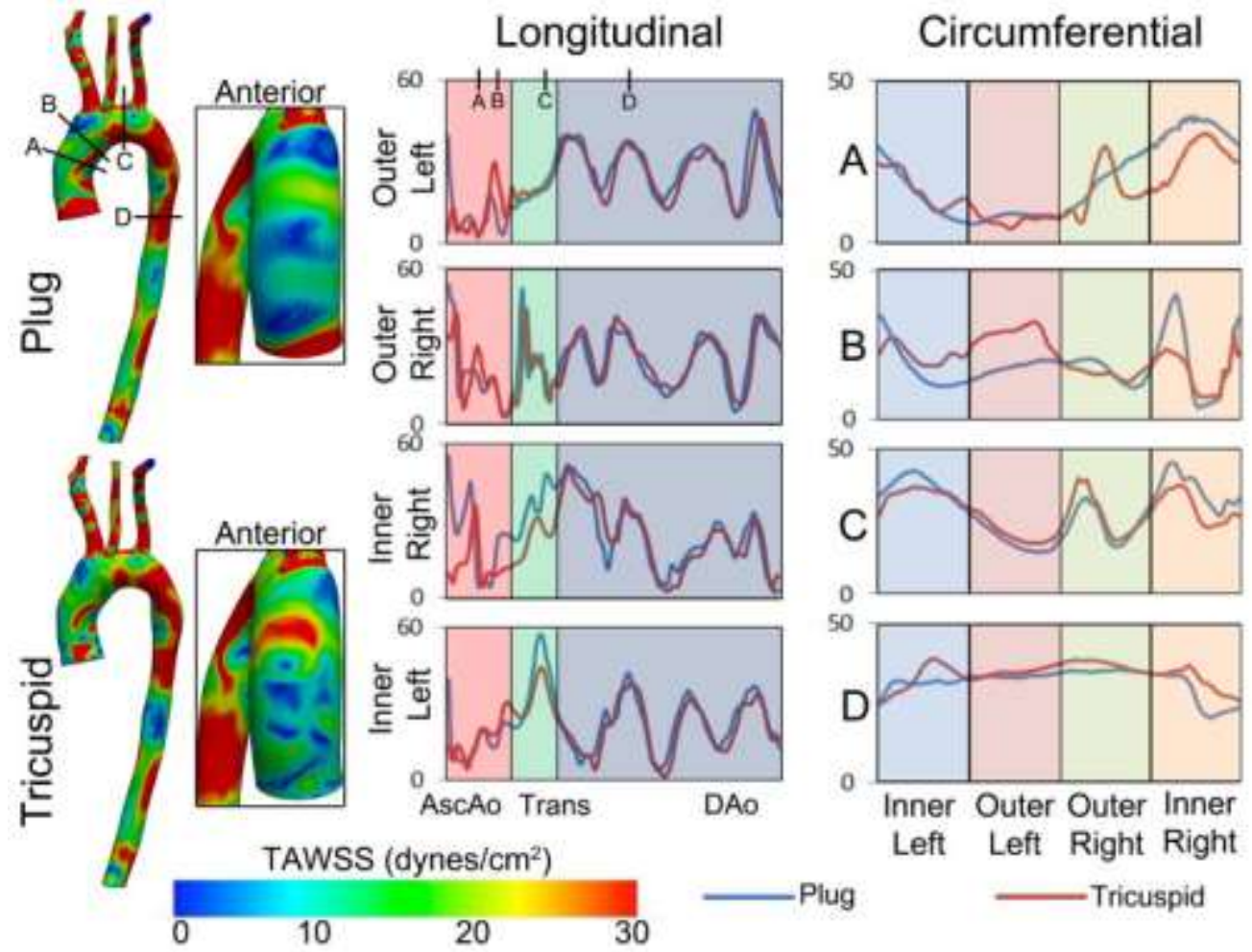

Figure 4

Comparison of TAWSS between a plug and tricuspid aortic valve inlet velocity profiles for the normal patient in example 1. Spatial distributions of TAWSS are shown on the vessel (left) and the inserts show the distribution along the anterior wall. Longitudinal and circumferential TAWSS was queried at specific locations to quantify regions of disparity between inlets.

Medical Engineering and Physics, Vol. 35, No. 6 (June 2013): pg. 723-735. DOI. This article is (c) Elsevier and permission has been granted for this version to appear in e-Publications@Marquette. Elsevier does not grant permission for this article to be further copied/distributed or hosted elsewhere without the express permission from Elsevier. 


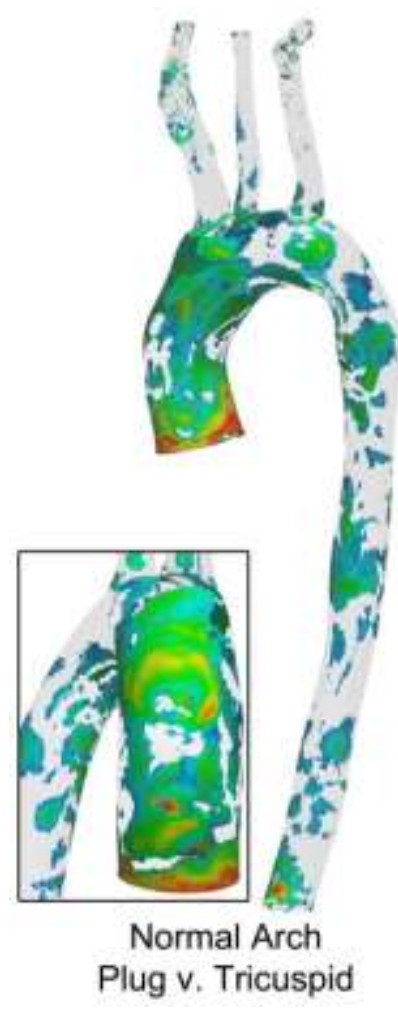

\section{Figure 5}

TAWSS differences between plug and TRI for the normal patient in example 1 (left) and plug and BAV for the CoA patient in example 2 (right). Opaque regions reveal the locations where the influence of the inflow waveform was greater than established levels of inter-observer variability. Insets show differences along the AscAo anterior wall.

\section{Oscillatory Shear Index}

Local longitudinal OSI was summarized for the inner and outer curvatures and anatomic left and right aortic surfaces in Figure 6. Disparity in OSI between inlet types was most pronounced along the outer left wall of the distal AscAo and along the inner wall more proximally, near the inlet. The proximal difference was most likely due to the presence of valve commissures in the TRI case that were absent in the plug simulation. These large differences normalized somewhat sooner than TAWSS, but differences still persisted into the transverse arch, and diminished substantially (to a maximum of $\sim 0.15$ ) in the dAo. OSI was also quantified circumferentially at two locations in the AscAo, the transverse arch, and dAo at locations that exhibited the largest differences longitudinally. Proximal differences in the AscAo 
were present along the inner left wall located $\sim 2.6 \mathrm{dAo}$ diameters proximal to the IA (Figure $6 \mathrm{~B}$, maximum of 0.36 ), while distal differences were mostly along the outer left wall $2 \mathrm{dAo}$ diameters proximal to IA (Figure 6D, maximum of 0.25 ).

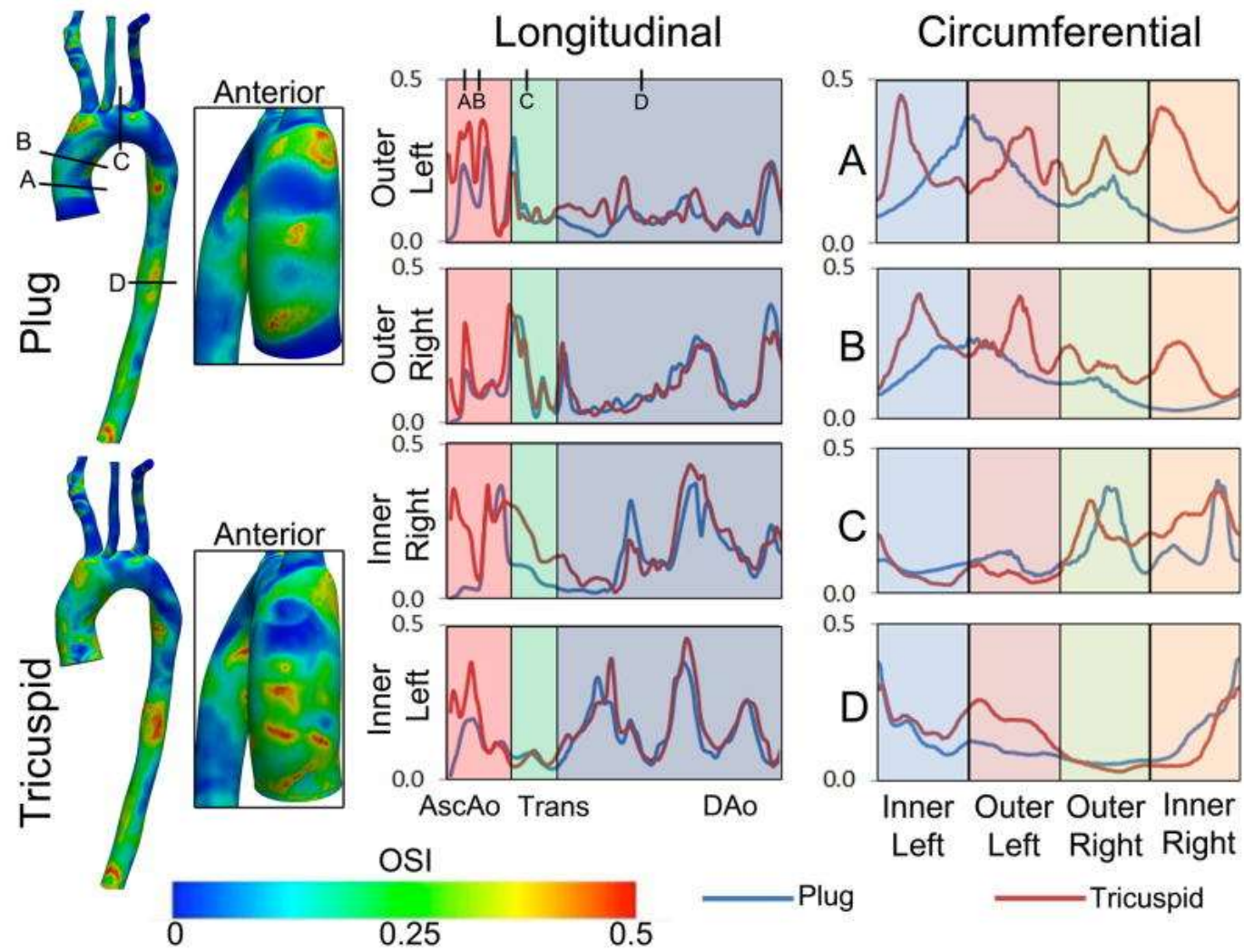

Figure 6

Comparison of OSI between a plug and tricuspid aortic valve inlet velocity profile for the normal patient in example 1. Spatial distributions of OSI are shown on the vessel (left) and the inserts show the distribution along the anterior wall. Longitudinal and circumferential OSI were queried at specific locations to quantify region of disparity between inlets.

TKE

The TRI inlet condition introduced more TKE in the AscAo and transverse arch Figure 7, top) as compared to a time-varying plug velocity profile, but values were low during peak systole and middeceleration. By way of comparison, the aortic arch itself introduces more pronounced TKE than the TRI AoV regardless of the time point within the cardiac cycle. TKE induced by the arch is prominent in the 
downstream dAo and values are accentuated by the TRI inlet condition, particularly during mid-deceleration and mid-diastole.
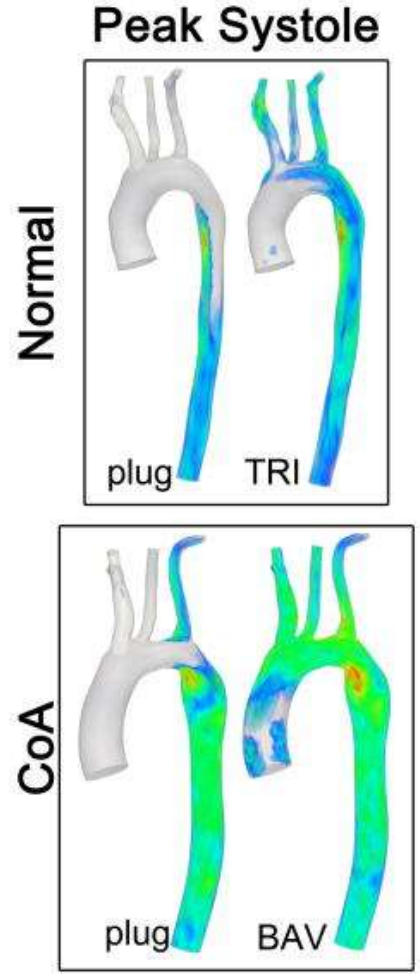
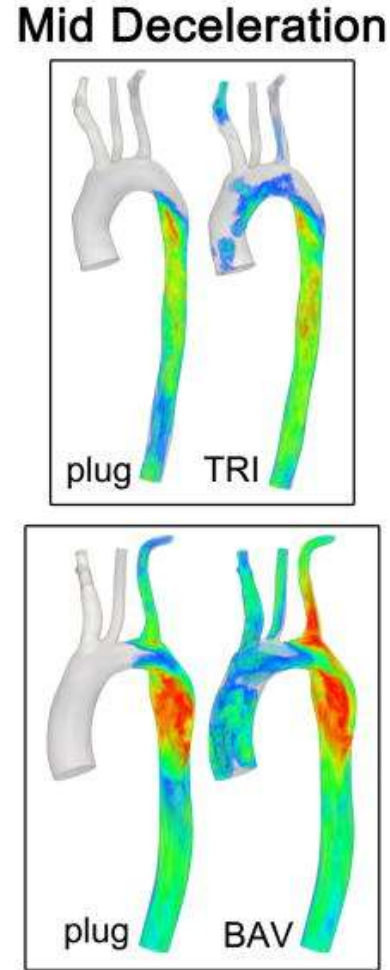
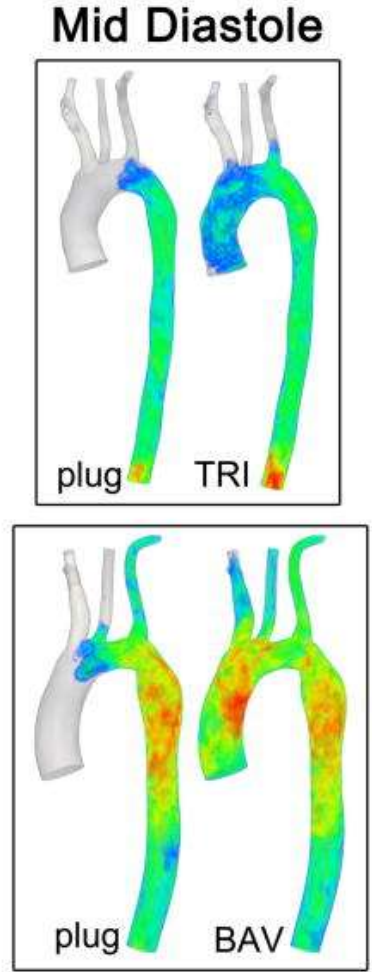

\section{Figure 7}

Turbulent kinetic energy (TKE) at peak systole (left column), mid-deceleration (center column), and mid-diastole (right column) for the normal patient from example 1 (top row) and the surgically repaired CoA/BAV patient from example 2 (bottom row). Comparisons were made between the time-varying plug inlet boundary conditions and the respective patient's AoV. Note: A logarithmic scale was used to visualize the large variation in TKE from different regions of the vessel. Transparent portions of the figure are those portions of the CFD models where TKE values were near zero.

Average TKE and TKE/KE were elevated throughout the thoracic aorta for the TRI inflow condition (Table 2). For example, TKE at peak systole was orders of magnitude less for the plug inflow (Plug: $\mathrm{TKE}=1.48 \mathrm{e}-5 \mathrm{~g} / \mathrm{cm} \cdot \mathrm{sec}^{2}, \mathrm{TKE} / \mathrm{KE}=5.24 \mathrm{e}-9 \mathrm{vs}$ TRI: TKE $=0.05$ $\left.\mathrm{g} / \mathrm{cm} \cdot \mathrm{sec}^{2}, \mathrm{TKE} / \mathrm{KE}=1.56 \mathrm{e}-5\right)$, but the differences were considerably reduced distal to the LSCA. At mid-deceleration, these indices increased in the AscAo and transverse arch, but were still orders of magnitude greater for the TRI AoV simulation (eg. TRI: TKE $=0.74$ $\mathrm{g} / \mathrm{cm} \cdot \mathrm{sec}^{2} ; \mathrm{TKE} / \mathrm{KE}=0.001 \mathrm{vs}$ plug: $\mathrm{TKE}=4.42 \mathrm{e}-5 \mathrm{~g} / \mathrm{cm} \cdot \mathrm{sec}^{2}$, $\mathrm{TKE} / \mathrm{KE}=2.79 \mathrm{e}-7$ ). 


\begin{tabular}{|c|c|c|c|c|}
\hline & \multicolumn{2}{|l|}{ Nermal } & \multicolumn{2}{|l|}{$\cos$} \\
\hline & Then & Trikespout & Phent & Biouspial \\
\hline \multirow{2}{*}{\multicolumn{5}{|c|}{ 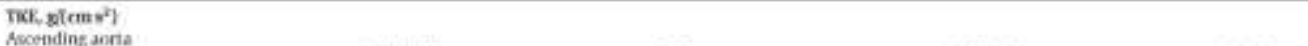 }} \\
\hline 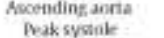 & & $n$ & $3255-067$ & \\
\hline Mid decoterstiven & $442-15$ & 0,24 & $1.958-05$ & ixs \\
\hline \multirow{2}{*}{\multicolumn{5}{|c|}{$\begin{array}{l}\text { Mid disstde } \\
\text { namsverse afth }\end{array}$}} \\
\hline & & & & \\
\hline & Writ-04 & 0.5 & 0.000 & 230 \\
\hline Midi decolecatice & 1.63E--04 & 0.62 & 368 & III. \\
\hline \multirow{2}{*}{\multicolumn{5}{|c|}{ Desonentine zori }} \\
\hline & & & & \\
\hline 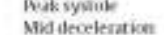 & 202 & 446 & 136 & 218 \\
\hline Mis ditist de & 18.1 & 350 & 122 & ins \\
\hline \multicolumn{5}{|l|}{$\mathrm{KE}, \mathrm{g}\left(\mathrm{cms} \mathrm{s}^{2}\right)$} \\
\hline Pesk sysole & 2830 & 3200 & 3540 & 3700 \\
\hline Mid deceteration & 154 & mis & 12000 & 100 \\
\hline & 18.3 & 75.. & $5 \$ 2$ & 175 \\
\hline \multicolumn{5}{|l|}{ Transwerse afth } \\
\hline Prak systok & 290 & 3060 & 5900 & 5500 \\
\hline Mid decotreatikn & 266 & 281 & 2530 & 2100 \\
\hline \multirow{2}{*}{\multicolumn{5}{|c|}{ Descendive arts }} \\
\hline & & & & \\
\hline Prak sysuit & 6008 & 910 & 4ะ1? & 4458 \\
\hline Mid deceleration & 1080 & 6.95 & 2892 & $298 \pi$ \\
\hline Mid dintale & 61.8 & 163 & 118 & $92 n$ \\
\hline \multicolumn{5}{|l|}{ TKE:KE } \\
\hline \multicolumn{5}{|l|}{ Mecendieg soria } \\
\hline Muk sysaik & $5.24 \mathrm{E}-00$ & $1.565-26$ & $20058-00$ & $8.628-04$ \\
\hline Mid decclenation & $27 y t-0 \%$ & 1.OLE- $\sigma 1$ & 1.6ZE - DS & 7.28E- $-\infty$ \\
\hline Mik distale & 1945.- 85 & 1.,7AE-OS & $6761-04$ & 9.2aE-0I \\
\hline \multicolumn{5}{|l|}{ Transverse anth } \\
\hline Peaksysouk & $137 \overline{E-07}$ & 2EE-O4 & 338E-05 & $4.21 \mathrm{E}-01$ \\
\hline Militecolesation & 6. $44-07$ & $1,008-2 \pi$ & $1,46 t-03$ & $1.456-\alpha$ \\
\hline \multirow{2}{*}{\multicolumn{5}{|c|}{ Shsirendine zarta }} \\
\hline & & & & \\
\hline 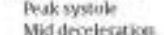 & $\begin{array}{l}2926-194 \\
2800-02\end{array}$ & 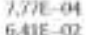 & $\begin{array}{l}2.865-03 \\
475-02\end{array}$ & 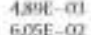 \\
\hline 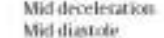 & $\begin{array}{l}2800-02 \\
277-01\end{array}$ & $\frac{6, A 1 E-02}{2,15 f \cdot 00}$ & Eise- 02 & 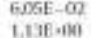 \\
\hline
\end{tabular}

\section{Example 2: Surgically Corrected CoA and BAV}

\section{Blood Flow Velocity}

Similar to Example 1, blood flow waveforms obtained in the AscAo, branch vessels, dAo also show good agreement between PCMRI measurements and those from plug and BAV simulations, especially throughout the thoracic aorta (Figure 8). Velocity profiles at various time points throughout the cardiac cycle show similar spatial values between the valve simulation and PC-MRI measurements. For example, the BAV case provides a better matching in mid-systolic and early diastolic velocity profiles near the CoA. 


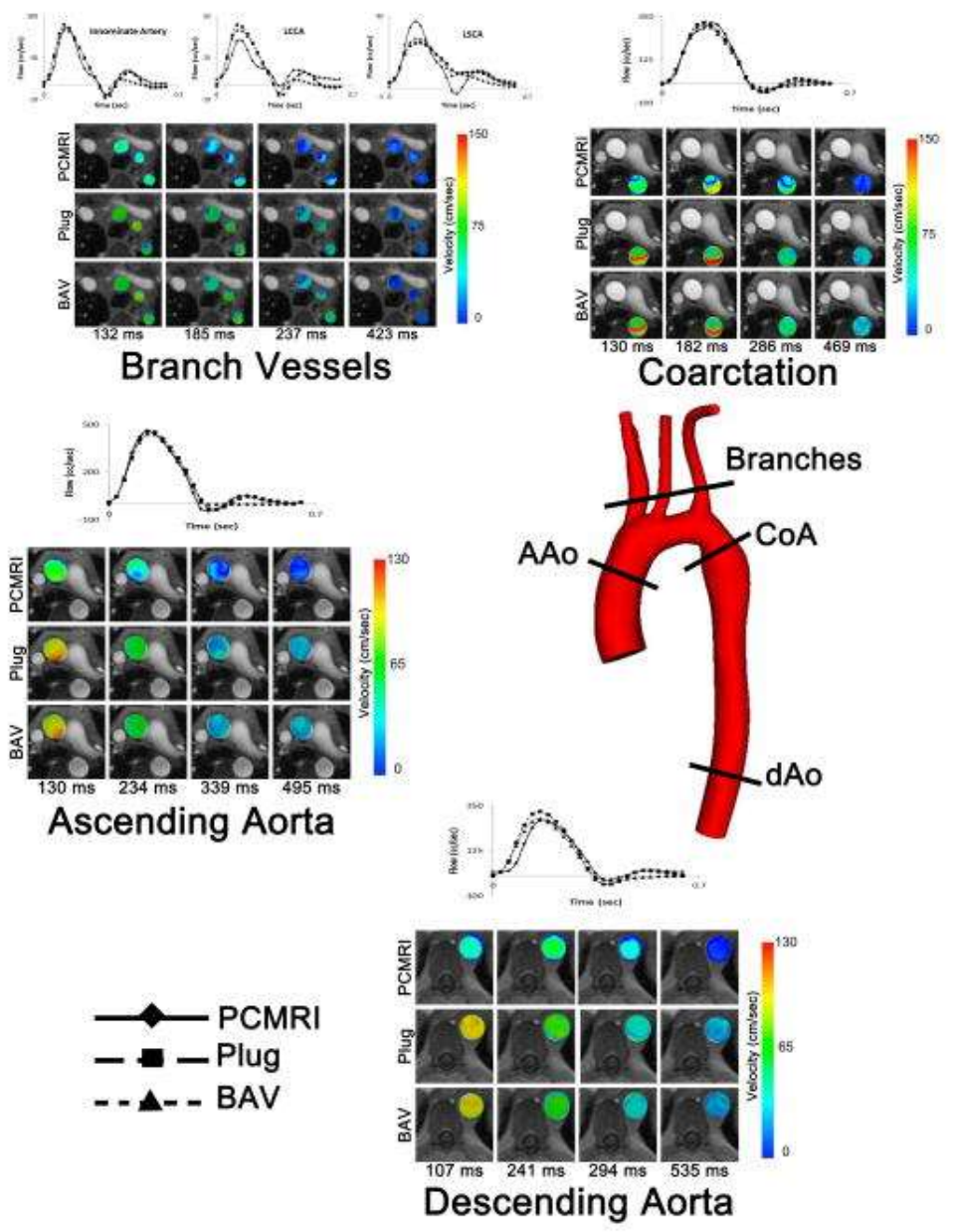

\section{Figure 8}

Comparison of blood flow velocity between PC-MRI (solid line), plug (dashed line), and BAV (dotted line) inlet conditions in the AscAo, proximal and distal $d A o$, innominate artery, LCCA, and LSCA for the surgically repaired CoA/BAV patient from example 2. Velocity profiles are also presented for 4 time points throughout the cardiac cycle (two during systole as well as in early and late diastole).

Velocity streamlines are parallel and fully attached to the vessel wall for the plug inflow condition (Figure 3, bottom) while substantial swirling and vortices were produced near the inlet for the BAV, the greatest of which occurred along the outer wall of the AscAo. Velocity profiles downstream show vectors that converge in the middle of the vessel and travel toward the outer wall as a result of the BAV (Figure 3 , inserts). 
NOT THE PUBLISHED VERSION; this is the author's final, peer-reviewed manuscript. The published version may be accessed by following the link in the citation at the bottom of the page.

\section{Wall shear stress}

Figure 9 shows local TAWSS along the longitudinal axis of the aorta and several specific circumferential locations where differences due to the valve are more pronounced. The greatest disparity in TAWSS was located along the outer left wall of the AscAo (27.9 dyn $/ \mathrm{cm}^{2}$ ) $\sim 2$ diameters proximal of the IA. The percent difference in TAWSS between inlets is shown in Figure 5 (right) with locations above the uncertainty introduced during the modeling process highlighted. The largest differences were present in the AscAo, but, unlike the normal arch, substantial differences existed into the transverse arch and proximal dAo.

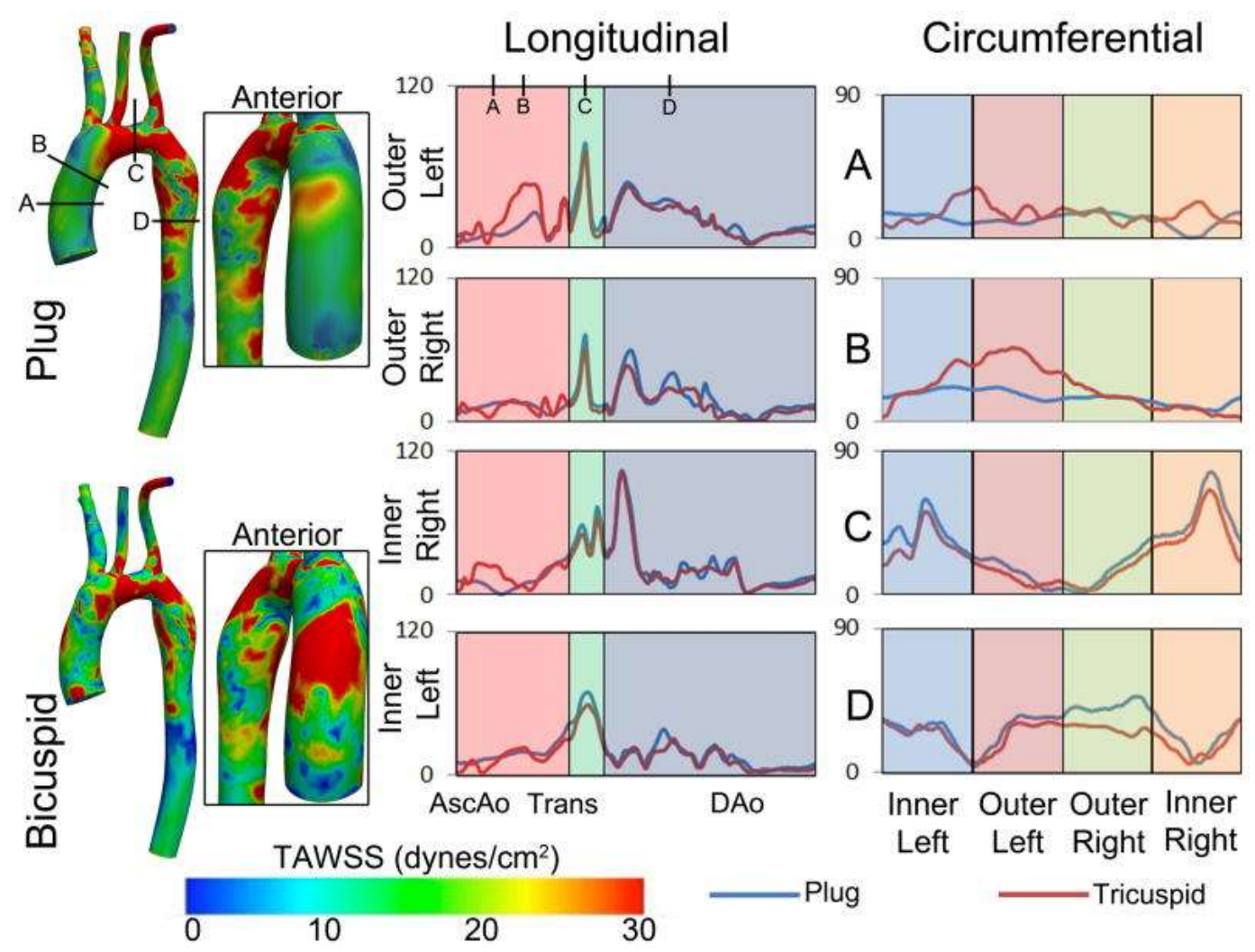

\section{Figure 9}

Comparison of TAWSS between a plug and bicuspid aortic valve inlet velocity profile for the patient with surgically corrected CoA in example 2. Spatial distributions of TAWSS is shown on the vessel (left) and inserts show the distribution along the anterior wall. Longitudinal and circumferential TAWSS was queried at specific locations to quantify regions of disparity between inlets. 
NOT THE PUBLISHED VERSION; this is the author's final, peer-reviewed manuscript. The published version may be accessed by following the link in the citation at the bottom of the page.

\section{Oscillatory Shear Index}

Figure 10 shows local OSI in the longitudinal and circumferential directions at specific locations throughout the thoracic aorta. Longitudinal differences were most apparent along the outer left and outer right wall of the AscAo, with substantial differences present proximally along the inner left. These differences begin to normalize in the transverse arch and are very similar throughout the dAo (maximum of $\sim 0.12$ ). The greatest variations in OSI circumferentially were located $\sim 3.76$ diameters proximal of the IA along the inner left wall (Figure $10 \mathrm{~A} ; 0.33$ ), and along the outer right wall $\sim 1.87$ diameters proximal to the IA (Figure 10B; 0.26).

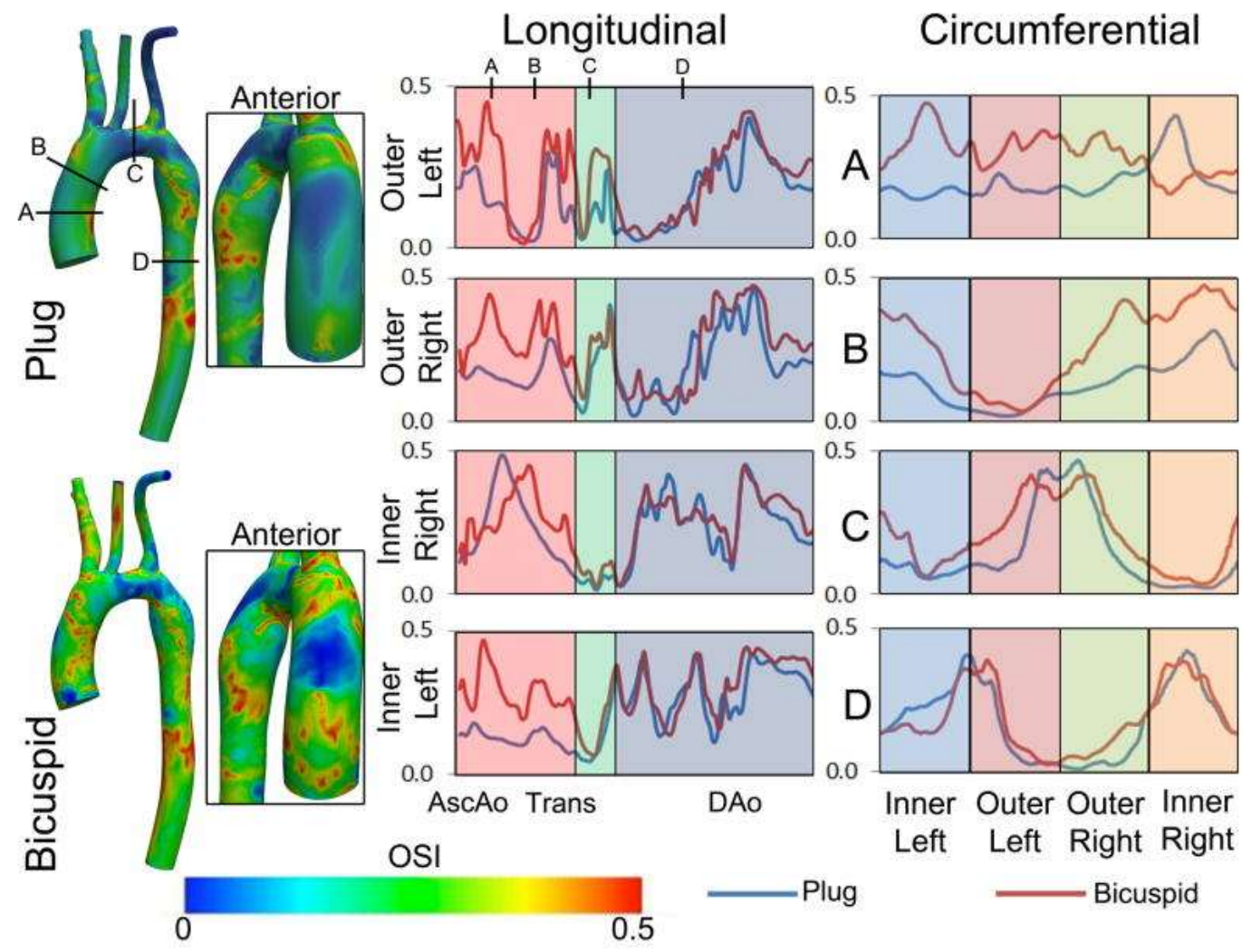

Figure 10

Comparison of OSI between a plug and bicuspid aortic valve inlet velocity profile for the CoA patient in example 2. Spatial distributions of OSI are shown on the vessel (left) and the inserts show the distribution along the anterior wall. Longitudinal and circumferential OSI were queried at specific locations to quantify region of disparity between inlets.

Medical Engineering and Physics, Vol. 35, No. 6 (June 2013): pg. 723-735. DOI. This article is (c) Elsevier and permission has been granted for this version to appear in e-Publications@Marquette. Elsevier does not grant permission for this article to be further copied/distributed or hosted elsewhere without the express permission from Elsevier. 
NOT THE PUBLISHED VERSION; this is the author's final, peer-reviewed manuscript. The published version may be accessed by following the link in the citation at the bottom of the page.

\section{Turbulent Kinetic Energy}

TKE patterns for the plug inlet were similar to the normal arch, but with elevated TKE in the dAo due to local flow disturbances near the region of repair (Figure 7, bottom). When the simulation in this example was run with a BAV, TKE was present throughout the AscAo at peak systole, increased during mid-deceleration, and was particularly prominent further into diastole.

Average TKE throughout the thoracic aorta was elevated for the BAV inflow condition (Table 2). For example, at peak systole and middeceleration, TKE was orders of magnitude less for the plug inflow (Plug: TKE $=7.25 \mathrm{e}-6 \mathrm{~g} / \mathrm{cm} \cdot \mathrm{sec}^{2}$, TKE $/ \mathrm{KE}=2.05 \mathrm{e}-9$ vs BAV: TKE $=3.24$ $\left.\mathrm{g} / \mathrm{cm} \cdot \mathrm{sec}^{2}, \mathrm{TKE} / \mathrm{KE}=8.62 \mathrm{e}-4\right)$. Curvature of the arch and modest residual narrowing just distal to the LSA caused these differences to drop considerably in the transverse arch and distal to the LSCA regardless of location in the cardiac cycle. However, TKE in the AscAo during mid-diastole was actually slightly higher in the AscAo (162 $\left.\mathrm{g} / \mathrm{cm} \cdot \mathrm{sec}^{2}\right)$ and transverse arch $\left(127 \mathrm{~g} / \mathrm{cm} \cdot \mathrm{sec}^{2}\right)$ than that induced in the dAo due to the arch and repair site $\left(105 \mathrm{~g} / \mathrm{cm} \cdot \mathrm{sec}^{2}\right)$.

\section{Discussion}

CFD studies of the thoracic aorta to date have typically introduced blood flow in one of two ways. In a preferred approach, PC-MRI is used to temporally sample the velocity profile downstream of the valve and input this measured profile directly into the model. While not directly including the valve, its impact can be manifested in the data that is obtained, but this requires appropriate through- and in-plane velocity encoding to adequately resolve flow features being input into the CFD model. This approach may be difficult to implement within the constraints of a clinical setting, as it can require specialized sequences not routinely implemented and obtains data that is more detailed than that commonly used in clinical diagnosis. One alternative approach has been to construct CFD models with their inlet beginning distal to the aortic sinuses, impose the measured blood flow waveform measured downstream as an assumed velocity profile at the model inlet, and allow the curvature of the arch to influence resulting flow patterns [26]. While this technique does not use the complete spatial velocity

Medical Engineering and Physics, Vol. 35, No. 6 (June 2013): pg. 723-735. DOI. This article is ( Elsevier and permission has been granted for this version to appear in e-Publications@Marquette. Elsevier does not grant permission for this article to be further copied/distributed or hosted elsewhere without the express permission from Elsevier. 
information, it does not require specialized sequences, minimizes the introduction of noise at the model inflow due to inadequate velocity encoding, and allows for improved temporal resolution compared to 3component PC-MRI [37]. The methods described here were therefore developed to include a more accurate representation of the impact of the AoV on CFD studies of the thoracic aorta using data obtained as part of a routine clinical imaging session. These methods were then applied to quantify the impact of valve morphology on aortic hemodynamics, identify regions most influenced by the inlet, including the location where valve influence is modest for two examples. The application of the current methods in these examples using both TRI and BAV AoVs demonstrates their utility across valve morphologies commonly occurring in patient populations such as CoA. The results of this pilot research provide several key observations to be studied in follow-up investigations. These observations are listed and discussed below.

1. The impact of AoV flow patterns in the thoracic aorta can be included within CFD simulations to identify regions of potentially deleterious hemodynamics.

2. When compared with their respective plug inlets, TAWSS were pronounced throughout the thoracic aorta for BAV, but generally limited to the AscAo for TRI. Differences in OSI were limited to the AscAo in both cases.

3. TRI and BAV differentially impact which portions of the AscAo will be exposed to potentially adverse TAWSS and OSI.

4. A plug inlet velocity profile greatly underestimates the amount of TKE present in the thoracic aorta compared to that introduced by the AoV.

\section{AoV flow patterns can be included in CFD simulations}

AoV morphology and function are known to influence the progression of disease in the AscAo [38]. Specifically, aortic dilatation and aneurysm formation in patients with aortic valve disease tends to occur at the sinotubular junction, AscAo, and IA [5, 38]. Other investigations have aimed to computationally investigate the influence of the valve on AscAo hemodynamics using simplified BAV and TRI [39]. The additional benefit of the current technique is its ability to

Medical Engineering and Physics, Vol. 35, No. 6 (June 2013): pg. 723-735. DOI. This article is @ Elsevier and permission has been granted for this version to appear in e-Publications@Marquette. Elsevier does not grant permission for this article to be further copied/distributed or hosted elsewhere without the express permission from Elsevier. 
impose blood flow velocities dictated by the patient's own detailed time-varying AoV. From a clinical perspective, differences in the AscAo due to valve morphology could aid in determining which patients should be closely followed as a result of adverse hemodynamic conditions introduced due to the patient's specific valve (BAV or TRI). The methods used in this investigation demonstrate a means of representing the impact of both the innate AoV disease, and the potential to implement various surgical corrections in silico to determine optimal outcomes in a patient-specific manner. For example, when surgeons seat a valve in the aortic annulus during a replacement procedure, the predominant guiding principles of valve positioning are to assure that flow into the coronary ostia is not impeded and to attempt to place the valve in the annulus with as little tilt as possible. Most prosthetic valves are bi-leaflet and the leaflet apparatus can be rotated in order to help assure the former goal is achieved. The current CFD work suggests additional aspects should be considered when positioning leaflets and, if verified, the methods presented here could lead to studies with significant clinical implications.

\section{TAWSS and OSI for CFD models with AoVs differ with varying severity from a plug inlet}

Localized alterations in TAWSS and OSI can cause cellular-level changes in the vasculature $[40,41]$. Endothelial cells typically align themselves with the direction of flow, but become disorganized when exposed to perturbations such as high OSI [40], which potentially lead to endothelial dysfunction and vascular disease. Thus, the ability to identify regions of altered hemodynamics is useful for understanding the local progression of disease.

The current investigation compared TAWSS difference maps between a time-varying plug velocity profile and patient-specific AoV inlet condition (BAV and TRI). For the normal arch in example 1, these differences were primarily confined to the AscAo and the influence of the inlet was very modest beyond the mid-transverse arch. While the largest differences were in the AscAo for the CoA/BAV patient in example 2, residual differences were also present throughout the transverse arch and dAo. These findings suggest studies interested in

Medical Engineering and Physics, Vol. 35, No. 6 (June 2013): pg. 723-735. DOI. This article is (C) Elsevier and permission has been granted for this version to appear in e-Publications@Marquette. Elsevier does not grant permission for this article to be further copied/distributed or hosted elsewhere without the express permission from Elsevier. 
the relationship between AoV pathology and indices of WSS should strive to include the AoV, but that CFD studies of patients with a TRI and a normal arch focusing on areas distal to the LSCA may be able to neglect the valve.

\section{TRI and BAV determine which luminal locations are exposed to adverse TAWSS and OSI}

Circumferential quantification of TAWSS and OSI were used to further elucidate differences with respect to inlet type and anatomic location. Indices of WSS were similar across inflow types (Figures 4 and 9), but varied substantially at several locations of the AscAo in each example. The current findings suggest the outer left and inner right portions of the AscAo are most influenced by the AoV, and may differ for patients with TRI vs BAV. Although these findings undoubtedly need to be confirmed in studies containing more patients, it is clear that including a TRI or BAV in CFD simulations can lead to different, and presumably more realistic, conclusions regarding TAWSS and OSI in the AscAo than an assumed time-varying plug velocity profile.

A prior computational study using simplified BAV and TRI valves revealed the outer AscAo wall is exposed to suboptimal WSS [42], similar to the current findings. Bauer et al also determined the region of highest peak systolic wall motion was located on the anteriolateral wall of the AscAo using Doppler ultrasound [5], while a previous 4D PC-MRI study revealed that patients with a BAV exhibited extensive vortex formation along the anterior and lateral AscAo wall [43]. While the current study also shows differences along the inner wall near the inlet as well as along the outer wall of the distal AscAo, future studies including the aortic sinuses and annulus would restrict these regions to the sinuses, and the additional curvature of the arch may result in a larger hemodynamic burden imposed on the outer wall of the AscAo. These results would likely have the potential to more closely resemble those found by Viscardi [42], Bauer [5], and Hope [43] mentioned above.

Medical Engineering and Physics, Vol. 35, No. 6 (June 2013): pg. 723-735. DOI. This article is (c) Elsevier and permission has been granted for this version to appear in e-Publications@Marquette. Elsevier does not grant permission for this article to be further copied/distributed or hosted elsewhere without the express permission from Elsevier. 


\section{TKE values from a plug inlet underestimate values obtained with Aovs}

As compared to simulations for both examples using plug inflow profiles that showed very little TKE in the AscAo during any portion of the cardiac cycle, indices of turbulence were noticeable for the TRI inlet example, but were less than those introduced by normal arch curvature. Conversely, the presence of a BAV amplified turbulence in the AscAo to at least the level caused by the curvature of the aorta and the residual narrowing present for the patient in example 2. Further analysis revealed this elevated TKE during mid-diastole is due to instabilities introduced as flow travels retrogradely to the AscAo from the head and neck vessels and similar findings may not be observed for all patients with a BAV. Nonetheless, this example elucidates the severity of disruptions that can be associated with a BAV, relative to normal, and suggests these instabilities introduced during systole persist longer into diastole.

Past studies of aneurysms in the abdominal aorta and arch have shown flow disturbances and turbulence influence parameters including BP, indices of WSS, vascular remodeling, and inflammation [44]. In vivo flow studies by Stein and Sabbah further showed that highly disturbed and turbulent flow could occur in the AscAo, but consistently occurred in individuals with abnormal AoVs [9]. Using PCMRI, Kilner [8] and Bogren [7] reported that healthy aortic arches experienced turbulence that is localized, transient, and of low intensity at rest, but the distal arch may be more susceptible to turbulent flow. These findings are consistent with those presented here and may explain why patients diagnosed with BAV have an increased risk of aortic dilatation. Turbulence causes large variations in the stresses experienced by the wall, similar to those seen during aneurysm formation and progression [45]. Therefore, CFD simulations including the impact of the AoV may provide insight into the possible adverse impact of TKE in the AscAo resulting from valve disease.

There are several potential study limitations. Results were considered mesh independent when TAWSS at several regions in the aorta changed $<1 \%$ between successive simulations. Thus, while it is possible that the results presented may differ for much larger meshes,

Medical Engineering and Physics, Vol. 35, No. 6 (June 2013): pg. 723-735. DOI. This article is (c) Elsevier and permission has been granted for this version to appear in e-Publications@Marquette. Elsevier does not grant permission for this article to be further copied/distributed or hosted elsewhere without the express permission from Elsevier. 
it is unlikely that the key observations would be altered. Also, although collateral circulation was not evident in the current CoA patient, the presence of collateral vessels from the upper extremities is common in CoA cases and would complicate the assignment of outlet boundary conditions since there does not seem to be any reports optimizing or tuning the selection of Windkessel parameters for collateral vessels to date. A rigid wall assumption was used to reduce computational expense, because precise material properties including the thickness and stiffness of the aorta were not available and to avoid the chance of obscuring results sought purely from including the influence of valve openings in CFD simulations. While theoretical or measured thickness and stiffness values found in literature could be used, these values may not accurately reflect the long-term effects of CoA and repair on aortic vasculature [46]. Previous work by our lab and others has shown varying thickness, elastic moduli, and regional tethering that should be accounted for in CFD simulations. Simulations were run with rigid walls since these advancements are not current possible within our laboratory. The current study replicates the AoV orifice accurately, but neglects valve tissue present in the flow domain. A study by Shadden et al [47] investigated fluid-structure interaction governing movement of the valve due to flowing blood. The study noted how the presence of valve leaflet tissue in the flow domain influenced the shape and direction of the AoV jet. Future studies will include the aortic annulus and sinuses, and possibly valve leaflet tissue, to more closely replicate morphology and associated flow patterns. The current research also only represents two case examples, and larger populations are therefore needed to determine if findings can be generalized.

The valve cases in the current investigation used a time-varying plug flow inlet with restricted cross-section. The blood flow values at any given time point were determined from the integrated PC-MRI phase data in the AscAo while the region for flow delineated by the valve was determined from the time-varying PC-MRI magnitude data. Corresponding plug flow velocity values were then scaled by the reduction in area imparted by the valve opening at a given time point. This approach does not use the pixel by pixel through- and in-plane phase information within the valve, but does allow for direct comparison to the approach of a time-varying plug inlet profile that has been implemented in other CFD studies to date. Similarly, while 
in-plane components of velocity are included when integrating velocities within regions delineated from the PC-MRI magnitude data, these components of the data are not directly input into the CFD model resulting in plug flow velocities essentially only introduced in the primary blood flow direction.

\section{Conclusions}

In summary, by including the influence of AoVs into CFD simulations, local WSS and TKE thought to be associated with longterm and post-operative morbidity were elucidated. Our findings underscore the benefits of including flow disturbances introduced by the AoV into CFD modeling, rather than applying traditional simplified practices of using an assumed velocity profile or overly simplified valve shapes. These CFD methods can now be applied to studies of larger populations to better understand hemodynamics in patients with both normal or diseased AoVs, and conceivably prosthetic valves as well. This approach may also be used for other diseases of the thoracic aorta besides CoA. Despite its limitations, this research elucidates how thoracic aortic simulation results may be influenced by the aortic valve in an attempt to advance the CFD methods one step closer to clinical reality. Inclusion of the influence of AoV morphology may enhance the acceptance of CFD models for surgical planning. By providing clinicians with critical information preoperatively (e.g. localized indices of WSS or TKE), the influence of a potential surgical or catheter-based treatment may be better understood than previously possible with traditional diagnostic imaging, thus improving patient outcomes.

\section{Acknowledgments}

The authors gratefully acknowledge Timothy Gundert MS for technical assistance.

Funding: This project was supported by an American Heart Association Predoctoral Fellowship award (to DCW, 0810093Z), the Alvin and Marion Birnschein Foundation, and NIH grant R15HL096096-01 (to JFL). This research was also funded in part by the National Science Foundation awards OCI-0923037 and CBET-0521602. No funding sources had any influence on study design, collection, analysis, or interpretation of data, manuscript preparation, or decision to submit for publication.

Medical Engineering and Physics, Vol. 35, No. 6 (June 2013): pg. 723-735. DOI. This article is (c) Elsevier and permission has been granted for this version to appear in e-Publications@Marquette. Elsevier does not grant permission for this article to be further copied/distributed or hosted elsewhere without the express permission from Elsevier. 
NOT THE PUBLISHED VERSION; this is the author's final, peer-reviewed manuscript. The published version may be accessed by following the link in the citation at the bottom of the page.

\section{Footnotes}

Competing interests: None declared

Ethical approval: Institutional Review Board approval was required from The Children's Hospital of Wisconsin and Marquette University (CHW 08/56, GC 638 and HR-1581, respectively). Patients and/or legal guardians were provided with written and verbal descriptions of the research and provided signed assent/consent for their medical data to be used in this study.

Publisher's Disclaimer: This is a PDF file of an unedited manuscript that has been accepted for publication. As a service to our customers we are providing this early version of the manuscript. The manuscript will undergo copyediting, typesetting, and review of the resulting proof before it is published in its final citable form. Please note that during the production process errors may be discovered which could affect the content, and all legal disclaimers that apply to the journal pertain.

\section{References}

1. Ward C. Clinical significance of the bicuspid aortic valve. Heart. 2000;83:81-5.

2. Warnes CA. Bicuspid aortic valve and coarctation: two villains part of a diffuse problem. Heart. 2003;89:965-6.

3. Ferencz C, Rubin JD, McCarter RJ, Brenner JI, Neill CA, Perry LW, et al. Congenital heart disease: prevalence at livebirth. The BaltimoreWashington Infant Study. American Journal of Epidemiology. $1985 ; 12: 31-6$.

4. Lloyd-Jones D, Adams RJ, Brown TM, Carnethon M, Dai S, De Simone G, et al. Heart disease and stroke statistics--2010 update: a report from the American Heart Association. Circulation. 2010;121:e46-e215.

5. Bauer M, Siniawski H, Pasic M, Schaumann B, Hetzer R. Different hemodynamic stress of the ascending aorta wall in patients with bicuspid and tricuspid aortic valve. Journal of Cardiac Surgery. 2006;21:218-20.

6. Weigang E, Kari Fabian A, Beyersdorf Friedhelm, Luehr Maximilian, Etz Christian D, Frydrychowicz Alex, Harloff Andrease, Markl Michael. Flow-sensitive four-dimensional magnetic resonance imaging: flow patterns in ascending aortic aneurysms. European Journal of Cardiothoracic Surgery. 2008;34:11-6.

7. Bogren $H$, Mohiaddin R, Yang G, Kilner $P$, Firmin D. Magnetic resonance velocity vector mapping of blood flow in thoracic aortic aneurysms and

Medical Engineering and Physics, Vol. 35, No. 6 (June 2013): pg. 723-735. DOI. This article is (C) Elsevier and permission has been granted for this version to appear in e-Publications@Marquette. Elsevier does not grant permission for this article to be further copied/distributed or hosted elsewhere without the express permission from Elsevier. 
NOT THE PUBLISHED VERSION; this is the author's final, peer-reviewed manuscript. The published version may be accessed by following the link in the citation at the bottom of the page.

grafts. Journal of Thoracic and Cardiovascular Surgery. 1995; 110:704-14.

8. Kilner PJ, Yang GZ, Mohiaddin RH, Firmin DN, Longmore DB. Helical and retrograde secondary flow patterns in the aortic arch studied by threedirectional magnetic resonance velocity mapping. Circulation. 1993;88:2235-47.

9. Stein $\mathrm{P}$, Sabbah H. Turbulent blood flow in the ascendign aorta of humans with normal and diseased aortic valves. Circulation Research. 1976;39:58-65.

10. Toro-Salazar $\mathrm{OH}$, Steinberger J, Thomas W, Rocchini AP, Carpenter B, Moller JH. Long-term follow-up of patients after coarctation of the aorta repair. American Journal of Cardiology. 2002;89:541-7.

11. O'Rourke MF, Cartmill TB. Influence of aortic coarctation on pulsatile hemodynamics in the proximal aorta. Circulation. 1971;44:281-92.

12. Pekkan K, Frakes D, De Zelicourt D, Lucas CW, Parks WJ, Yoganathan AP. Coupling pediatric ventricle assist devices to the Fontan circulation: simulations with a lumped-parameter model. Asaio J. 2005;51:61828.

13. Socci L, Gervaso F, Migliavacca F, Pennati G, Dubini G, Ait-Ali L, et al. Computational fluid dynamics in a model of the total cavopulmonary connection reconstructed using magnetic resonance images. Cardiol Young. 2005;15 (Suppl 3):61-7.

14. LaDisa JF, Jr, Alberto Figueroa C, Vignon-Clementel IE, Kim HJ, Xiao N, Ellwein LM, et al. Computational simulations for aortic coarctation: representative results from a sampling of patients. J Biomech Eng. 2011;133:091008.

15. Yeung JJ, Kim HJ, Abbruzzese TA, Vignon-Clementel IE, Draney-Blomme MT, Yeung KK, et al. Aortoiliac hemodynamic and morphologic adaptation to chronic spinal cord injury. J Vasc Surg. 2006;44:125465.

16. Frydrychowicz A, Stalder AF, Russe MF, Bock J, Bauer S, Harloff A, et al. Three-dimensional analysis of segmental wall shear stress in the aorta by flow-sensitive four-dimensional-MRI. J Magn Reson Imaging. 2009;30:77-84.

17. Wentzel JJ, Corti R, Fayad ZA, Wisdom P, Macaluso F, Winkelman MO, et al. Does shear stress modulate both plaque progression and regression in the thoracic aorta? Human study using serial magnetic resonance imaging. J Am Coll Cardiol. 2005;45:846-54.

18. Pizarro C, De Leval MR. Surgical variations and flow dynamics in cavopulmonary connections: A historical review. Semin Thorac Cardiovasc Surg Pediatr Card Surg Annu. 1998;1:53-60.

Medical Engineering and Physics, Vol. 35, No. 6 (June 2013): pg. 723-735. DOI. This article is (C) Elsevier and permission has been granted for this version to appear in e-Publications@Marquette. Elsevier does not grant permission for this article to be further copied/distributed or hosted elsewhere without the express permission from Elsevier. 
19. Ou P, Bonnet D, Auriacombe L, Pedroni E, Balleux F, Sidi D, et al. Late systemic hypertension and aortic arch geometry after successful repair of coarctation of the aorta. Eur Heart J. 2004;25:1853-9.

20. Wilson N, Wang K, Dutton R, Taylor CA. A software framework for creating patient specific geometric models from medical imaging data for simulation based medical planning of vascular surgery. Lect Notes Comput Sci. 2001;2208:449-56.

21. Les AS, Shadden SC, Figueroa AC, Park JM, Tedesco MM, Herfkens RJ, et al. Quantification of Hemodynamics in Abdominal Aortic Aneurysms During Rest and Exercise Using Magnetic Resonance Imaging and Computational Fluid Dynamics. Annals of Biomedical Engineering. 2010;38:1288-313.

22. Heiberg E, Markenroth K, Arheden H. Validation of free software for automated vessel delineation and MRI flow analysis. Journal of Cardiovascular Magnetic Resonance. 2007;9:375-6.

23. Tang BT, Cheng CP, Draney MT, Wilson NM, Tsao PS, Herfkens RJ, et al. Abdominal aortic hemodynamics in young healthy adults at rest and during lower limb exercise: quantification using image-based computer modeling. Am J Physiol Heart Circ Physiol. 2006;291:H668-76.

24. Bernstein MA, Zhou XJ, Polzin JA, King KF, Ganin A, Pelc NJ, et al. Concomitant gradient terms in phase contrast MR: analysis and correction. Magn Reson Med. 1998;39:300-8.

25. Pelc LR, Pelc NJ, Rayhill SC, Castro LJ, Glover GH, Herfkens RJ, et al. Arterial and venous blood flow: noninvasive quantitation with MR imaging. Radiology. 1992;185:809-12.

26. LaDisa JF, Jr, Dholakia RJ, Figueroa CA, Vignon-Clementel IE, Chan FP, Samyn MM, et al. Computational simulations demonstrate altered wall shear stress in aortic coarctation patients treated by resection with end-to-end anastomosis. Congenit Heart Dis. 2011;6:432-43.

27. Tan FPP, Borghi A, Mohiaddin RH, Wood NB, Thom S, Xu XY. Analysis of flow patterns in a patient-specific thoracic aortic aneurysm model. Comput Struct. 2009;87:680-90.

28. Schaefer B, Lewin M, Stout K, Gill E, Prueitt A, Byers $P$, et al. The bicuspid aortic valve: an integrated phenotypic classification of leaflet morphology and aortic root shape. Heart. 2008;94:1634-8.

29. Vignon-Clementel IE, Figueroa CA, Jansen KE, Taylor CA. Outflow boundary conditions for three-dimensional finite element modeling of blood flow and pressure in arteries. Comput Methods Appl Mech Eng. 2006;195:3776-96.

30. Sahni O, Muller J, Jansen KE, Shephard MS, Taylor CA. Efficient anisotropic adaptive discretization of the cardiovascular system. Comput Methods Biomech Biomed Engin. 2006;195:5634-55.

Medical Engineering and Physics, Vol. 35, No. 6 (June 2013): pg. 723-735. DOI. This article is (c) Elsevier and permission has been granted for this version to appear in e-Publications@Marquette. Elsevier does not grant permission for this article to be further copied/distributed or hosted elsewhere without the express permission from Elsevier. 
31. Muller J, Sahni O, Li X, Jansen KE, Shephard MS, Taylor CA. Anisotropic adaptive finite element method for modeling blood flow. Comput Methods Biomech Biomed Engin. 2005;8:295-305.

32. Hughes T. The Finite Element Method: Linear Static and Dynamic Finite Element Analysis. Mineola, NY: Dover Publications; 2000.

33. Ku DN, Giddens DP, Zarins CK, Glagov S. Pulsatile flow and atherosclerosis in the human carotid bifurcation. Positive correlation between plaque location and low oscillating shear stress. Arteriosclerosis. 1985;5:293-302.

34. Moore JA, Steinman DA, Holdsworth DW, Ethier CR. Accuracy of Computational Hemodynamics in Complex Arterial Geometries Reconstructed from Magnetic Resonance Imaging. Annals of Biomedical Engineering. 1999;27:32-41.

35. Bieging ET, Frydrychowica A, Wentland A, Landgraf BR, Johnson KM, Wieben $O$, et al. In Vivo Three-Dimensional MR Wall Shear Stress Estimation in Ascending Aortic Dilation. Journal of Magnetic Resonance Imaging. 2011;33:589-97.

36. Gundert TJ, Shadden SC, Williams AR, Koo B-K, Feinstein JA, LaDisa JF. A Rapid and Computationally Inexpensive Method to Virtually Implant Current and Next-Generation Stents into Subject-Specific Computational Fluid Dynamics Models. Annals of Biomedical Engineering. 2011:1423-37.

37. Lotz J, Meier C, Leppert A, Galanski M. Cardiovascular flow measurement with phase-contrast MR imaging: basic facts and implementation. Radiographics. 2002;22:651-71.

38. Cotrufo $M$, Della Corte $A$. The association of bicuspid aortic valve disease with asymmetric dilatation of the tubular ascending aorta: identification of a definite syndrome. Journal of Cardiovascular Medicine. 2009;10:291-7.

39. Tan FPP, Borghi A, Mohiaddin RH, Wood NB, Thom S, Xu XY. Analysis of flowpatterns in a patient-specific thoracic aorticaneurysm model. Computers and Structures. 2009;87:680-90.

40. Lee A, Grahm D, Cruz S, Ratcliffe A, Karlon W. Fluid shear stress-induced alignment of cultured vascular smooth muscle cells. Journal of Biomechanical Engineering. 2002;124:37-43.

41. Liu S, Tang D, Tieche C, Alkema P. Pattern formation of vascular smooth muscle cells subject to nonuniform fluid shear stress: mediation by gradient cell density. American Journal of Physiology - Heart and Circulatory Physiology. 2003;285:H1072-H80.

42. Viscardi F, Vergara C, Antiga L, Merelli S, Veneziani A, Puppini G, et al. Comparative finite element model analysis of ascending aortic flow in bicuspid and tricuspid aortic valve. Artificial Organs. 2010;34:111420.

Medical Engineering and Physics, Vol. 35, No. 6 (June 2013): pg. 723-735. DOI. This article is (c) Elsevier and permission has been granted for this version to appear in e-Publications@Marquette. Elsevier does not grant permission for this article to be further copied/distributed or hosted elsewhere without the express permission from Elsevier. 
43. Hope MD, Meadows AK, Hope TA, Ordovas KG, Reddy GP, Alley MT, et al. Evaluation of bicuspid aortic valve and aortic coarctation with 4D flow magnetic resonance imaging. Circulation. 2008;117:2818-9.

44. Giddens D, Mabon R, Cassanova R. Measuremnets of disordered flow distal to subtotal vascular stenoses in the throacic aortas of dogs. Circulation Research. 1976:112-9.

45. Berguer R, Bull JL, Khanafer K. Refinements in Mathematical Models to Predict Aneurysm Growth and Rupture. Annals of the New York Academy of Sciences. 2006;1085:110-6.

46. Menon A, Wendell DC, Wang H, Eddinger T, Toth J, Dholakia RJ, et al. A coupled experimental and computational approach to quantify deleterious hemodynamics, vascular alterations, and mechanisms of long-term morbidity in response to aortic coarctation. Journal of Pharmacological and Toxicological Methods. 2012;65:18-28.

47. Shadden SC, Astorino M, Gerbeau J-F. Computational analysis of an aortic valve jet with LAgrangian coherent structures. Chaos.

$2010 ; 20: 017512$.

Corresponding author: John F. LaDisa, Jr., PhD, Assistant Professor of Biomedical Engineering, Marquette University, Adjunct Assistant Professor of Pediatrics and Cardiovascular Medicine, Children's Hospital and the Medical College of Wisconsin, 1515 West Wisconsin Ave, room 206, Milwaukee, WI 53233, Phone: 414-288-6739, Fax: 414-2887938, Email: ude.etteuqram@asidal.nhoj 